Fadel, N. - A eterna busca da verdade

\title{
A eterna busca da Verdade em Die Lehrlinge zu Sais, de Novalis
}

\author{
Natália Corrêa Porto Sanches Fadel ${ }^{1}$
}

\begin{abstract}
The purpose of this essay is to undergo an investigation geared towards identifying the consolidation of the symbolized Upper or Ideal Truth illustrated by the figure of the goddess Saïs in the fragmentary novel Die Lehrlinge zu Saïs, from Novalis, written in 1801. As part of our approach, we traced a parallel between the allegorical use of Saïs myth by Novalis and in Schiller's poem Das verschleierte Bild zu Saïs, aiming at a better characterization of Novalis' concept of the Ideal Truth. Lastly, we analyzed the fairy tale Hyazinth und Rosenbluite, which is part of the novel Die Lehrlinge zu Saïs, where it is possible to envisage the finding of the Ideal Truth searched by the poets of German Early Romanticism, especially by Novalis.
\end{abstract}

Keywords: German Early Romanticism; Novalis; Die Lehrlinge zu Saïs; Schiller; fairy tale.

Resumo: O presente artigo tem por objetivo investigar como se dá a questão da busca do conhecimento ilustrada pela figura da deusa Saïs no fragmento de romance de Novalis Die Lehrlinge zu Saïs, escrito em 1801. Em nossa investigação, traçamos um paralelo entre o uso alegórico do mito de Saïs em Novalis e no poema de Schiller Das verschleierte Bild zu Saïs, a fim de melhor caracterizar o conceito de verdade novalisiano. Por fim, procuramos analisar o conto de fadas Hyazinth und Rosenblüte, que se encontra no interior da narrativa em questão, uma vez que nele se dá o encontro ideal da Verdade almejado pelos poetas do primeiro-romantismo alemão, em especial, por Novalis.

Palavras-chave: Frühromantik; Novalis; Die Lehrlinge zu Saïs; Schiller; conto de fadas.

\footnotetext{
${ }^{1}$ Doutoranda em Literatura Alemã pela Universidade Livre de Berlim.E-Mail: natifadel@ hotmail.com

Pandaemonium germanicum 15/2010.1, p. 37-49 - www.fflch.usp.br/dlm/alemao/pandaemoniumgermanicum
} 
Fadel, N. - A eterna busca da verdade

Zusammenfassung: Ziel dieses Aufsatzes ist die Darstellung einer Untersuchung des fragmentarischen Romans Die Lehrlinge zu Saïs, von Novalis (1801). Im Mittelpunkt steht die Frage, inwieweit sich die Erkenntnis der Wahrheit in der Figur der Göttin Saïs verwirklicht. Um Novalis' Begriff der Wahrheit besser zu erläutern, wurde Schillers Gedicht Das verschleierte Bild zu Saïs parallel dazu betrachtet. Zuletzt wird auch eine Analyse des Märchens Hyazinth und Rosenblüte angeführt, das in Novalis' Werk Die Lehrlinge zu Saïs vorkommt, denn dieses Märchen illustriert die Erkenntnis der Wahrheit, die von den Frühromantikern gesucht wurde, besonders von Novalis.

Schlüsselwörter: Frühromantik; Novalis; Die Lehrlinge zu Saïs; Schiller; Märchen.

\section{Saïs e a busca do conhecimento}

O parágrafo que abre a narrativa Die Lehrlinge zu Saïs remete-nos claramente à noção de escritura contida na natureza, a partir da qual o homem deveria voltar-se para dentro de si em busca de sua verdade por meio do auto-conhecimento, a fim de se reconciliar com a natureza e, desta forma, ser capaz de decifrar os hieróglifos sagrados nela contidos:

Mannigfache Wege gehen die Menschen. Wer sie verfolgt und vergleicht, wird wunderliche Figuren entstehen sehn; Figuren, die zu jener großen Chiffernschrift zu gehören scheinen, die man überall, auf Flügeln, Eierschalen, in Wolken, im Schnee, in Kristallen und in Steinbildungen, auf gefrierenden Wassern, im Innern und Äußern der Gebirge, der Pflanzen, der Tiere, der Menschen, in den Lichtern des Himmels, auf berührten und gestrichenen Scheiben von Pech und Glas, in den Feilspänen um den Magnet her, und sonderbaren Konjunkturen des Zufalls, erblickt. In ihnen ahndet man den Schlüssel dieser Wunderschrift, die Sprachlehrer derselben. (Novalis 1981: 95).

Este seria, então, o propósito dos Discípulos de Saïs: encontrar a verdade. O caminho até ela, no entanto, não poderia ser-lhes dado, já que cada um deles deveria buscá-la à sua maneira. Ora, para Novalis, de nada serviria ter o caminho previamente dado: é necessário buscá-lo, refletir sobre o que se encontra, sobre a vida, sobre cada palavra, cada gesto. Aquele que realmente buscasse sua verdade, a encontraria:

Pandaemonium germanicum 15/2010.1, p. 37-49 - www.fflch.usp.br/dlm/alemao/pandaemoniumgermanicum 
Fadel, N. - A eterna busca da verdade

A letra é apenas um auxílio da comunicação filosófica, cuja essência própria consiste no suscitamento de uma determinada marcha de pensamentos. O falante pensa produz [sic] - o ouvinte reflete - reproduz. As palavras são um meio enganoso do pré-pensar - veículo inidôneo de um estímulo determinado, específico. O genuíno mestre é um indicador de caminho. Se o aluno é de fato desejoso da verdade, é preciso apenas um aceno, para fazê-lo encontrar aquilo que procura. [...] O desenvolvimento analítico do tema é só para preguiçosos ou inexercitados. Estes últimos precisam aprender a voar através dele e manter-se numa direção determinada. (NovALIS 2001: 109. Grifo nosso.)

Diante disto, embora os discípulos sejam guiados por uma espécie de mentor - der Lehrer-, ele não se julga capaz de apontar o caminho da verdade, já que esta só seria encontrada dentro de cada um. Como nota Lothar Pikulik, "Die Lehrlinge andererseits werden von ihm (dem Lehrer) nicht nur geführt, sondern sind gehalten, selbst zu entdecken, was das Rechte sei” (PIRULIK 1992: 249). Assim, cabe-lhe apenas ouvir e ponderar as idéias dos discípulos acerca da vida, do amor e da verdade, reforçando sempre a importância de se entrar em comunhão com a natureza para se chegar ao conhecimento, simbolizado pela deusa Saïs:

Den Lehrer kann und mag ich nicht begreifen. Er ist mir just so unbegreiflich lieb. Ich weiß es, er versteht mich, er hat nie gegen mein Gefühl und meinen Wunsch gesprochen. Vielmehr will er, dass wir den eigenen Weg verfolgen, weil jeder neue Weg durch neue Länder geht, und jeder endlich zu diesen Wohnungen, zu dieser heiligen Heimat wieder führet. (NovALIS 1981: 98)

Num jogo de espelhamento infinito, no qual homem e mundo se definem - die Wechselrepräsentationen -, o homem encontraria dentro de si a Verdade do mundo, adquirindo assim a sabedoria buscada, a qual o levaria à compreensão da Natureza. Nas palavras de Novalis:

Wir träumen von Reisen durch das Weltall - ist denn das Weltall nicht in uns? Die Tiefen unseres Geistes kennen wir nicht - Nach Innen geht der geheimnisvolle Weg. In uns, oder nirgends ist die Ewigkeit mit ihren Welten- der Vergangenheit und Zukunft. Die Außenwelt ist die Schattenwelt- Sie wirft ihren Schatten in das Lichtreich. (NovALIS 2006: 8) 
Fadel, N. - A eterna busca da verdade

Consolida-se, então, um exemplo do Ordo Inversus novalisiano, de maneira que "Man sieht hier, wie relativ das Herausgehen und Hineingehen ist. Was wir Hineingehen nennen, ist eigentlich Herausgehen- eine Wiederannahme der anfänglichen Gestalt” (NovALIS 2006:15).

Desta forma, partindo da noção fichteana do reconhecimento do Eu através do Não$\mathrm{Eu}$, isto é, de tudo aquilo que não é Eu, Novalis concebe o auto-entendimento a partir do mundo exterior e vice-versa. Como afirma Márcio Seligmann-Silva (2004), "a visão do saber como o avesso do não-saber e, portanto, da identidade como jogo de determinação e diferença fez com que Novalis acentuasse reiteradas vezes o fato de que só há definição através da saída do objeto a ser definido, só há a se não-a.” Ou ainda, citando o próprio Novalis: "O eu puro nós vemos, portanto, sempre fora - o eu puro é o objeto. Ele está em nós e nós o vemos ao mesmo tempo fora de nós" (NovAlis apud SELIGMANN-SILVA 2004).

Segundo PfEFFERKORN (1988), a Verdade almejada pelos discípulos é simbolizada na figura de Saïs, deusa-mãe da terra, da morte e da sabedoria. É conhecida também como Isis, Ishtar, Astarte ou Danaä. A deusa Saïs seria a personificação da natureza.

Encontra-se no Egito o templo erguido à deusa Isis, onde se verificam as inscrições: "Eu sou tudo, o que há, o que será; nenhum mortal jamais levantou meu véu." (PFEFFERKORN 1988: 123. Tradução nossa). A partir desta inscrição, Schiller reconheceu a deusa enquanto representação simbólica do espírito da natureza e da verdade, escrevendo o poema Das verschleierte Bild zu Saïs., o qual descreve a trajetória de um jovem escolhido para guardar o templo da deusa Saïs devido à sua inteligência fora do comum: "Ein Jüngling, den des Wissens heißer Durst/ Nach Saïs in Ägypten trieb, der Priester/ Geheime Weisheit zu erlernen, hatte/ Schon manchen Grad mit schnellem Geist durcheilt...” (SCHILLER 2007). Movido pela sede de conhecimento e pela curiosidade, o jovem desacata as leis da deusa e levanta seu véu em busca do verdadeiro conhecimento. Como punição, a deusa lhe tira a vida no mesmo instante: "Nun, - fragt ihr - 'und was zeigte sich ihm hier?'/ Ich weiß es nicht. Besinnungslos und bleich, / So fanden ihn am andern Tag die Priester/ Am Fußgestell der Isis ausgestreckt./ Was er allda gesehen und erfahren,/ Hat seine Zunge nie bekannt.“" (SCHILLER 2007).

Pandaemonium germanicum 15/2010.1, p. 37-49 - www.fflch.usp.br/dlm/alemao/pandaemoniumgermanicum 
Fadel, N. - A eterna busca da verdade

O jovem não podia levantar o véu da deusa, de forma que sua verdade deveria serlhe revelada no momento certo por vontade de Saïs. Assim sendo, o jovem vê-se despreparado para tanto conhecimento e morre prostrado aos pés da imagem da deusa.

Embora Novalis também faça uso da imagética relacionada à deusa Isis a fim de representar a Sabedoria, o tratamento que se verifica em Die Lehrlinge zu Sä̈s difere muito do que se observa no poema de Schiller. Primeiramente, o jovem escolhido por Novalis não é aquele que se destaca pela inteligência. Ao contrário, trata-se do jovem aparentemente mais despreparado, aquele que menos compreende o que seu mentor diz. Após uma noite sozinho em meio à natureza, ele descobre a verdade do mundo, simbolizada na pedra exótica por ele encontrada, a qual pode ser comparada à Pedra Filosofal:

In unsere Mitte trat er bald, und brachte, mit unaussprechlicher Seligkeit im Antlitz, ein unscheinbares Steinchen von seltsamer Gestalt. Der Lehrer nahm es in die Hand, und küsste ihn lange, dann sah er uns mit nassen Augen an und legte dieses Steinchen auf einen leeren Platz, der mitten unter andern Steinen lag, gerade wo wie Strahlen viele Reihen sich berührten. [...] Uns war, als hätten wir im Vorübergehen eine helle Ahndung dieser wunderbaren Welt in unseren Seele gehabt. (NOVALIS 1981: 97)

Na Alquimia, a Pedra Filosofal - der Stein der Weisen - é o elemento fundamental na conclusão das operações alquímicas para a fabricação do ouro. Para Cardinal, ela simboliza a maturidade do discípulo que a encontrou, consolidando, assim, o ritual de passagem ao conhecimento: "The finding of the Stein der Weisen signifies the self-realisation and spiritual maturation of the student [...] The precious blue stone is clear image of love and revelation.” (CARDINAL 1973: 128-9).

De acordo com PFEFFERKORN (1988), no momento em que veem a pedra, os discípulos têm uma espécie de pressentimento da unidade total do universo, de maneira que a pedra representaria tal unidade centralizadora quando é posicionada em meio às demais pedras. Assim,

Being the nodal point of convergence of so many rows of stones, it functions as a symbol and sign of unity. And the diverse objects of nature - all her stones and stars, flowers and animals, and even mankind - are, because of the pebble's

Pandaemonium germanicum 15/2010.1, p. 37-49 - www.fflch.usp.br/dlm/alemao/pandaemoniumgermanicum 
Fadel, N. - A eterna busca da verdade

symbolic power, suddenly perceived as hieroglyphic representations of that unity. The double character of all natural phenomena is thus made evident: everything is both symbol and sign of something other than itself and also simply itself as natural object. (PFEFFERKORN 1988: 123)

A escolha do jovem mais ingênuo para representar o encontro do homem com a Verdade explica-se pelas palavras do próprio Novalis em um de seus fragmentos: "Je unwissender man von Natur ist, desto mehr Kapazität für Wissen. Jede neue Erkenntnis macht einen viel tiefern, lebendigern Eindruck. Man bemerkt dieses deutlich beim Eintritt in eine Wissenschaft. Daher verliert man durch zu vieles Studieren die Kapazität.“ (2006: 28). Nota-se nesta passagem ainda, a crítica ao conhecimento científico, bem como a indireta exaltação da figura do poeta, já que este, por meio da observação sensível, seria o único capaz de compreender a natureza e seus mistérios.

É válido ressaltar também que em Die Lehrlinge zu Saïs o encontro com Saïs ou Isis dá-se de fato apenas no interior de outra narrativa contida no texto. Trata-se do conto de fadas (Märchen) Hyazinth und Rosenblüte, do qual trataremos com maior atenção mais adiante. Aqui, Hyazinth sai em busca de Isis, a fim de obter o conhecimento da verdade. Ao contrário do que acontece com o jovem no poema de Schiller, Hyazinth é encorajado a levantar o véu da deusa, e quando o faz, encontra Rosenblüte, seu verdadeiro amor. Por meio do amor (die Liebe), o homem aproximar-se-ia do conhecimento total.

É importante esclarecer o conceito de amor para Novalis, mais uma vez ligado à idéia de Wechselrepräsentationen. Ora, pois se daria no outro, no ser amado, o local de reconhecimento de si mesmo, isto é, é na figura do Não-Eu, em que o Eu se reflete e se descobre, já que somente com a saída de si, o Eu pode enxergar-se plenamente. Por outro lado, o outro, ou Não-eu, estaria ao mesmo tempo dentro do Eu, dentro de si, de maneira que um se reflete no outro reciprocamente. Nas palavras de Pikulik:

Liebe - nach romantischer Vorstellung heißt es nicht Haben, Besitzen, sondern Sehnsucht, der Zug des Herzens in die geheimnisvolle Ferne. [...] Wenn Liebe zudem in der Beziehung des Ich zum Anderen besteht und diese Beziehung, was Novalis stets voraussetzt, auf der Freiheit und Selbständigkeit der Partner beruht, so muss die ursprüngliche naive Einheit zwischen Hyazinth und Rosenblüte auch deshalb in die Trennung und Zweiheit übergehen, damit Ich wahrhaft das Du erkennt, über das Du aber auch sich selbst, als Ich, findet. (PIKULIK 1992: 252-3)

Pandaemonium germanicum 15/2010.1, p. 37-49 - www.fflch.usp.br/dlm/alemao/pandaemoniumgermanicum 
Fadel, N. - A eterna busca da verdade

Diante de todo o exposto, poder-se-ia concluir que a viagem ao templo de Saïs nada mais seria do que a viagem interior às profundezas de cada um: "Dass das Geheimnis sich anderseits als Du enthüllt, heißt zugleich, dass das ganz Andere das heimatliche Vertraute ist. Die Reise in die Freiheit ist somit Heimkehr, der Weg nach Hause.“ (PIKULIK 1998: 253).

\section{conto e fadas Hyazinth und Rosenblüte}

Em determinado momento da narrativa Die Lehrlinge zu Saïs, um dos viajantes, ou ainda, possivelmente o próprio narrador em conflito consigo mesmo, procura convencer-se de suas teorias românticas contando a história de Hyazinth e Rosenblüte (Jacinto e Botãozinho de Rosa). A história tem a estrutura das narrativas de conto de fadas, contendo os elementos do conto maravilhoso descrito por André JOLES:

No conto, o prodígio do maravilhoso é a única possibilidade que se tem de estarmos seguros de que se deixou de existir a imoralidade da realidade.[...] A ação localizase sempre "num país distante, longe, muito longe daqui", passa-se "há muito, muito tempo", ou então o lugar é em toda e nenhuma parte, a época sempre e nunca.[...] Quando o conto adquire os traços da história [...] perde uma parte de sua força. A localização histórica e o tempo histórico avizinham-no da realidade imoral e quebram o fascínio do maravilhoso e imprescindível. O mesmo ocorre com os personagens, que também devem ter essa segurança indeterminada contra a qual se desfaz a realidade imoral. (JOLES 1976: 202)

Ainda no que se refere à estrutura, trata-se de um conto de fadas artístico, já que não foi concebido nos moldes dos contos de fadas populares, como se observa na coletânea de contos de fadas dos irmãos Grimm do início do século XIX. De acordo com Karin Volobuef, os contos de fadas artísticos se diferem dos populares em vários aspectos. Em primeiro lugar, não são fruto da tradição oral, isto é, concebidos pela coletividade, mas sim da imaginação de um determinado autor. Além disso, muitas vezes são usados para veicular

Pandaemonium germanicum 15/2010.1, p. 37-49 - www.fflch.usp.br/dlm/alemao/pandaemoniumgermanicum 
Fadel, N. - A eterna busca da verdade

determinadas idéias, sendo carregados de símbolos e /ou alegorias usados para ilustrar as teses de seu autor:

É durante o Romantismo que se produz o maior número de contos artísticos na Alemanha [...] o conto de fadas constitui para os românticos um campo fértil para a expansão de sua fantasia, sendo capaz de comportar um grande potencial simbólico e veicular idéias e sentimentos típicos da época, traduzindo a emergência de novos valores estéticos e a redescoberta da própria identidade nacional. (VOLOBUEF 1993: 105)

Dentro da esfera dos contos de fadas artísticos, há ainda uma subclassificação observada por Hugo Moser (apud VolobUEF 1993:105), segundo a qual o conto de fadas de Novalis em questão seria classificado enquanto conto de fadas artístico portador de idéias, devido ao profundo teor alegórico, muito distante do conto de fadas popular.

É importante notar ainda, que é a partir do Romantismo que o conto de fadas passa a ser aceito enquanto forma literária, sendo colocado no centro da poética romântica. Segundo Eloá HeISE e Ruth RöHL,

a razão dessa preferência é quase lógica, uma vez que o conto de fadas responde exemplarmente à tendência antimimética do Romantismo: desenvolve-se na esfera do maravilhoso, sem compromisso com a realidade empírica. Por outro lado, permite a aproximação entre tradição popular (Volksmärchen - conto de fadas popular) e tradição intelectual (Kunstmärchen - conto de fadas artístico), observando como o romance, o conceito de poesia universal. (HEISE/RÖHL 1986: 44)

O conto de fadas de Novalis ilustra a vida no que seria a Idade de Ouro, na qual todos os homens viviam em plenitude, comunicando-se com as pedras e os animais: "Höhlen und Wälder waren sein liebster Aufenthalt, und dann sprach er [Hyazinth] immerfort mit Tieren und Vögeln, mit Bäumen und Felsen, natürlich kein vernünftiges Wort, lauter närrisches Zeug und Totlachen" (NovaLIS 1981: 108).

Jacinto e Botãozinho de Rosa vivem um amor verdadeiro. No entanto, Jacinto é acometido por uma súbita tristeza, da qual ninguém consegue livrá-lo e que só faz 
Fadel, N. - A eterna busca da verdade

aumentar. Sua melancolia faz com que ele se afaste cada vez mais de Botãozinho de Rosa, que se resigna a esperar.

Ambos os personagens são descritos como possuidores de uma beleza clássica, porém não são dotados de profundidade psicológica, o que é característico dos contos de fadas:

Er [Hyazinth] war recht bildschön, sah aus wie gemalt, tanzte wie ein Schatz. Unter den Mädchen war Eine, ein köstliches, bildschönes Kind, sah aus wie Wachs, Haare wie goldene Seide, kirschrote Lippen, wie ein Püppchen gewachsen, brandrabenschwarze Augen. (NovALIS 1981: 109).

Certo dia, Jacinto conhece um viajante que lhe conta sobre suas viagens repletas de seres maravilhosos e lhe oferece um livro que, segundo ele, nenhum homem seria capaz de ler. O viajante é descrito como sendo um bruxo, ou mago, cuja figura causava repúdio em Botãozinho de Rosa.

O livro que Jacinto ganhara representaria o conhecimento total. Para compreendê-lo, Jacinto deveria ir ao encontro de Isis, a fim de obter a sua Verdade. É interessante notar que em Heinrich von Ofterdingen, Novalis explora ainda mais a figura do livro enquanto símbolo do conhecimento total:

Heinrich blieb mit Freuden bei den Büchern [...] Er blättert mit unendlicher Lust umher. Endlich fiel ihm ein Buch in die Hände, das in einer fremden Sprache geschrieben war, die ihm einige Ähnlichkeit mit der lateinischen und italienischen zu haben schien. Er hätte sehnlichst gewünscht, die Sprache zu kennen, denn das Buch gefiel ihm vorzüglich ohne dass er eine Silbe davon verstand. Es hatte keinen Titel, doch fand er noch beim Suchen einige Bilder. Sie dünkte ihm ganz wunderbar bekannt, und wie er recht zusah, entdeckte er seine eigene Gestalt ziemlich kenntlich unter den Figuren. [...] Die letzten Bilder waren dunkel und unverständlich [...] der Schluss des Buches schien zu fehlen. (NovALIs 2006: 90-1)

Jacinto decide, então, ir a busca da deusa Isis. Ele não sabe onde encontrá-la, mas segue seu caminho guiado por um anseio (Sehnsucht) inexplicável: "a paz fugiu de mim, e com ela se foram o coração e o amor. Tenho de ir procurá-los. Gostaria de dizer-vos aonde vou, mas eu próprio ignoro.” (NovALIS 1989: 57). Por meio dessa passagem, percebe-se que Jacinto 


\section{Fadel, N. - A eterna busca da verdade}

tem consciência de que precisa se reintegrar ao mundo de onde veio, de modo que inicia sua busca. Durante sua peregrinação, percebe-se que a paisagem ao seu redor se transforma de acordo com seu estado de espírito. Aos poucos, a angústia de Jacinto é substituída pela vontade de retornar para casa:

Im Anfange kam er durch raues, wildes Land, Nebel und Wolken warfen sich ihm in den Weg, es stürmte immerfort; dann fand er unabsehliche Sandwüsten, glühenden Staub, und wie er wandelte, so veränderte sich auch sein Gemüt, die Zeit wurde ihm lang und die innere Unruhe legte sich, er wurde sanfter und das gewaltige Treiben in ihm allgemach zu einem leisen, aber starken Zuge, in dem sein ganzes Gemüt auflöste. Es lag viele Jahre hinter ihm. Nun wurde die Gegend auch wieder reicher und mannigfaltiger, die Luft lau und blau, der Weg ebener... (NOVALIS 1981: 111)

Jacinto não tinha se dado conta de que, na verdade, estava aos poucos se reaproximando de casa. A paisagem ao seu redor era-lhe mais agradável, porque também já lhe era conhecida Durante todo o percurso, Jacinto pediu ajuda a diversos seres que cruzaram seu caminho, a fim de encontrar o templo de Ísis, no entanto, não conseguia sequer entendê-los. Nas proximidades de sua casa, encontra finalmente um grupo de flores com quem consegue conversar e que lhe apontam o caminho. Para sua surpresa, ao levantar o véu da deusa, descobre nela Botãozinho de Rosa. Numa atmosfera que nos remete àquela do sonho, Jacinto reencontra sua paz:

Wunderlich führte ihn der Traum durch unendliche Gemächer voll seltsamer Sachen auf lauter reizenden Klängen und in abwechselnden Akkorden. Es dünkte ihm alles so bekannt und doch in niegesehener Herrlichkeit, da schwand auch der letzte irdische Anflug, wie in Luft verzehrt, und er stand vor der himmlischen Jungfrau, da hob er den leichten, glänzenden Schleier, und Rosenblüte sank in seine Arme. (NovALIS 1981: 112)

Ora, Jacinto afastou-se de casa, de seu mundo de plenitude, no qual compreendia todos os seres e as coisas, em busca da "chave do conhecimento". No entanto, caiu na ignorância ao sair à procura dele, ou de si mesmo. Assim, em vez de se tornar mais sábio, como muitos esperariam, Jacinto torna-se cego para as verdadeiras belezas da vida, deixando de ouvir a 
Fadel, N. - A eterna busca da verdade

voz dos animais e de se integrar plenamente ao Mundo Original. Com isso, conhece a infelicidade.

Vale ressaltar a importância do sonho para os românticos, já que por meio dele o homem estaria apto a alcançar o Todo Original. O universo onírico seria, assim, uma maneira de transcender ao passado mítico: "Selbst der Schlaf ist nichts als die Flut jenes unsichtbaren Weltmeers, und das Erwachen das Eintreten der Ebbe.“ (NovALIS 1981: 122).

A história de Jacinto e Botãozinho de Rosa ilustra a idéia de que o "conhecimento" afasta o homem de sua essência, do caminho da verdadeira felicidade. Desta forma, sábio seria aquele que pudesse enxergar a necessidade de se buscar a reconciliação com seu passado mítico, o que poderia ser alcançado por meio da integração com a natureza, com seu eu-interior e por meio da Arte. A criação seria, então, fonte do verdadeiro conhecimento:

Billig stellt der Künstler die Tätigkeit obenan, denn sein Wesen ist Tun und Hervorbringen mit Wissen und Willen, und seine Kunst ist, sein Werkzeug zu allem gebrauchen, die Welt auf seine Art nachbilden zu können, und darum wird das Prinzip seiner Welt Tätigkeit, und seine Welt seine Kunst. Auch hier wird die Natur in neuer Herrlichkeit sichtbar, und nur der gedankenlose Mensch wirft die unleserlichen, wunderlich gemischten Worte mit Verachtung weg. (NOVALIS 1981: 120).

Seria interessante lembrar que, até o Romantismo, a Arte era concebida primordialmente enquanto mimeses, isto é, imitação. Todavia, para os românticos, a Arte deixa de ser apenas representação para formar seu próprio universo - a Arte passa a ser autônoma, completa em si mesma. De acordo com Eloá Heise e Ruth Röhl,

O idealismo subjetivo de Fichte vai influenciar os românticos em seu conceito da autonomia da criação literária. O poeta cria mundos, mas estes não são uma cópia da Natureza e, sim, autônomos. Os românticos opõem-se radicalmente ao conceito de mimese (imitação), que vigora na literatura até o século XVIII. (HEISE/RÖHL 1986: 43)

Desta maneira, o poeta teria o dom de alcançar a transcendência por meio de sua arte, de forma a ser considerado verdadeiro sábio, como um profeta: "Nur Dichter sollten mit dem 
Fadel, N. - A eterna busca da verdade

Flüssigen umgehen, und von ihm der glühenden Jugend erzählen dürfen; die Werkstätten wären Tempel und mit neuer Liebe würden die Menschen ihre Flamme und ihre Flüsse verehren und sich ihrer rühmen." (NovALIS 1981:123).

Por fim, conclui-se que a narrativa em questão, ao mesmo tempo em que ilustra o pensamento novalisiano acerca da linguagem, da arte e da natureza, cumpre a trajetória esperada nos contos de fadas, já que, de acordo com PROPP:

Podemos chamar de conto de magia todo desenvolvimento narrativo que, partindo de um dano ou uma carência e passando por funções intermediárias, termina com o casamento ou outras funções utilizadas como desenlace. A função final pode ser a recompensa, a obtenção do objeto procurado ou, de modo geral, a reparação do dano, o salvamento da perseguição, etc. (PROPP 2006: 90)

\section{Referências bibliográficas}

FICHTE, J.G. Von der Sprachfähigkeit und dem Ursprunge der Sprache. In: Sämmtliche Werke. Berlin: Verlag von Veit und Comp., 1846.

HEISE, Eloá; RÖHL, Ruth. História da Literatura Alemã. São Paulo: Ed. Ática, 1986.

JOLES, André. Formas Simples. São Paulo: Cultrix, 1976.

LÉVY, Ann-Déborah. Ísis. In: BRUNEL, Pierre (org.). Dicionário de mitos literários. Rio de Janeiro: José Olympio Editora, 2004, 498-503.

MAAS, Wilma Patricia M.D. A crítica primeiro-romântica a Os anos de aprendizado de Wilhelm Meister - Friedrich Schlegel e Novalis. In: O Cânone Mínimo. $O$ Bildungsroman na história da literatura. São Paulo: Editora UNESP, 1999, 113132.

MÄHL, Hans-Joachin. Die Idee des goldenen Zeitalters im Werk des Novalis. Tübingen: Max Niemeyer Verlag, 1994.

NOVALIS (Friedrich von Hardenberg). Die Lehrlinge zu Saïs. In: Novalis Werke. Herausgegeben und kommentiert von Gerhard Schulz. München: Verlag C. H. Beck. 1981, 96-127. . Os discípulos em Saïs. Tradução de Luís Bruhein. Lisboa: Hiena, 1989. . Fragmente und Studien. In: NOVALIS. Fragmente und Studien. Die Christenheit oder Europa. Stuttgart: Reclam, 2006, 05-66. . Heinrich von Ofterdingen. Stuttgart: Reclam, 2006. . Hymnen an die Nacht. Heinrich von Ofterdingen. Augsburg: Goldmann Verlag, 1994.

Pandaemonium germanicum 15/2010.1, p. 37-49 - www.fflch.usp.br/dlm/alemao/pandaemoniumgermanicum 
Fadel, N. - A eterna busca da verdade

. Pólen. Fragmentos, diálogos, monólogo. (Trad. de Rubens Rodrigues Torres Filho). São Paulo: Iluminuras, 2001.

Werke, Tagebücher und Briefe. Organizado por Hans-Joachin Mähl e Richard Samuel. München: Karl Hansen Verlag, 1978 ss. v. 1-3.

PFEFFERKORN, Kristin. Novalis: A Romantic Theory of Language and Poetry, 1998.

PIKULIK, Lothar. Frühromantik - Epoche - Werke - Wirkung. München: Verlag C.H. Beck, 1992.

PROPP,V. L. Morfologia do Conto maravilhoso. Rio de Janeiro: Editora Forense Universitária, 2006.

SCHILLER. Das verschleierte Bild zu Saïs. http://gutenberg.spiegel.de/schiller/moses/moses.htm (26/07/2007).

SCHLEGEL, Friedrich. Discurso sobre a mitologia. In: Conversa sobre Poesia e outros fragmentos. Trad. Victor-Pierre Stirnimann. São Paulo: Iluminuras, 1994.

. Fragmentos da revista Athenäum. (trad. e notas de Willi Bolle). In: CHIAMPI, Irlemar (coord.). Fundadores da modernidade. São Paulo: Ática, 1998, 38-44.

SELIGMANN-SILVA, Márcio. Ler o livro do mundo. Walter Benjamin: Romantismo e crítica literária. São Paulo: Iluminuras, 1999.

. Friedrich Schlegel e Novalis: Poesia e Filosofia. Terceira Margem. Estética, Filosofia e Ciência nos Séculos XVIII e XIX. Revista do Programa de PósGraduação em Ciência da Literatura. http://www.ciencialit.letras.ufrj.br/terceiramargemonline/numero10/vi.html (31/01/2008).

UERLINGS, Herbert. Novalis (Friedrich von Hardenberg). Stuttgart: Reclam, 1998.

VOLOBUEF, Karin. Um Estudo do Conto de Fadas. Revista de Letras. São Paulo, 1993, 99-114. 